\title{
Correction: Retinal detachment following cataract phacoemulsification-a review of the literature
}

\section{Hamza Qureshi ${ }^{1,2} \cdot$ David H. W. Steel ${ }^{1,3}$}

Published online: 28 October 2019

(C) The Author(s), under exclusive licence to The Royal College of Ophthalmologists 2019

\section{Correction to: Eye}

https://doi.org/10.1038/s41433-019-0575-z

published online 01 October 2019
Since the online publication of this article, the authors realised that three data points were missing from Figure 1. This has now been corrected. The authors apologise for any inconvenience caused.

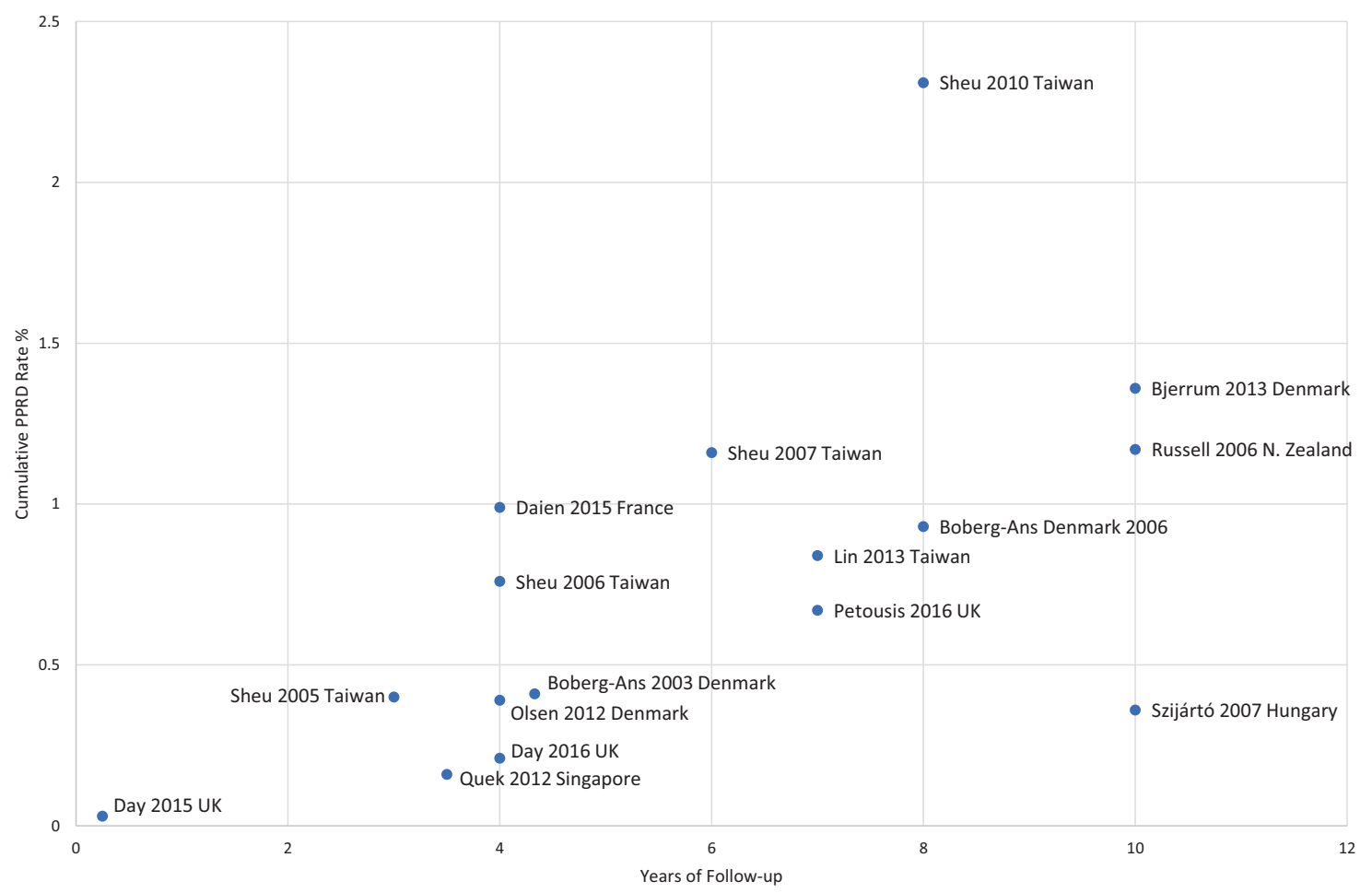

Fig. 1 Cumulative PPRD incidence as reported by the 16 studies included in this review

David H. W. Steel

David.steel@ncl.ac.uk

Institute of Genetic Medicine, Newcastle University, Newcastle Upon Tyne, UK
2 Royal Victoria Infirmary, Queen Victoria Road, Newcastle Upon Tyne, UK

3 Sunderland Eye Infirmary, Queen Alexandra Road, Sunderland, UK 